\title{
OS NOTÁVEIS \\ DO INSTITUTO DE EDUCAÇÃO: \\ PROFESSORES CATEDRÁTICOS \\ DO CURSO NORMAL \\ NOS ANOS 1950-601
}

\author{
Sonia de Castro Lopes ${ }^{\mathrm{II}}$

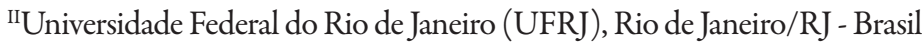

\section{Resumo}

Este artigo focaliza as trajetórias dos professores catedráticos Vicente Tapajós(1917-1998) e Evanildo Bechara (1928), referenciados pelas ex-alunas como "notáveis" e que compuseram o corpo docente do Instituto de Educação em uma época identificada como o período áureo da instituição. Resultados dessa investigação apontam para a hierarquização do corpo docente do Instituto a partir de critérios que contemplam o nível de formação desses professores, a forma de acesso à carreira, a valorização social das disciplinas ministradas, as redes de sociabilidade nas quais estavam envolvidos, além do volume e alcance das obras didáticas produzidas.

Palavras-chave: Instituto de Educação, Professores catedráticos, Formação de Professores.

Abstract

This articles discusses the career development of two teachers - Vicente Tapajós (1917-1998) and EvanildoBechara (1928) - who belonged to the faculty of Instituto de Educação do Rio de Janeiro during the so-called 'golden days' of the

1 Versão preliminar deste texto foi apresentada no VII Congresso Brasileiro de História da Educação, ocorrido na UFMT, Cuiabá, em maio de 2013.

Educ. Foco, Juiz de Fora, v. $21, n .2$, p.423-446, maio/ago. 2016 
institution. The findings of this investigation show an organizational structure of the Instituto based on a set of criteria that comprised teacher qualification, career entrance motivation, the social worth of the subjects every teacher taught, the social networks teachers belonged to and the amount and outreach of their publications.

Keywords: Instituto de Educação, Fully-qualified teachers, Teacher qualification.

A profissão docente constitui hoje um dos principais eixos temáticos dos estudos sobre história da educação, tanto no que se refere ao conhecimento sobre modelos e práticas formadoras quanto em relação às dimensões práticas do trabalho e condições sociais do ofício do professor ${ }^{2}$. A pesquisa histórica vem sendo cada vez mais solicitada, não apenas para explicar como se configurou o papel dos docentes no passado, mas também para ajudar a entender as inúmeras situações que hoje condicionam a formação desses profissionais, bem como o exercício de sua atividade.

Este artigo apresenta resultados de uma pesquisa que propõe investigar a estrutura e o perfil identitário do corpo docente do curso normal do Instituto de Educação do Rio de Janeiro entre as décadas de 1950-1960, seus percursos de formação e trajetórias profissionais. Ao longo da investigação foi possível mapear três categorias distintas de professores, por nós denominados:

a) os "notáveis" ou "inesquecíveis" ${ }^{3}$ - portadores de

2 A importância do tema história da profissão docente justifica-se por sua inserção como eixo temático nos principais congressos de História da Educação. A afirmativa partiu de um levantamento realizado nos Anais dos últimos Congressos Brasileiros de História da Educação (2011, 2013 e 2015), do último Congresso Ibero americano de História da Educação (CIHELA, 2014) e dos últimos Congressos Luso-Brasileiros de História da Educação (COLUBHE, 2012; 2014).

3 Convencionou-se denominar esta categoria pelo termo "notáveis" ou "inesquecíveis" a partir de entrevistas produzidas com ex-alunas da instituição que demonstraram profundo orgulho pelo fato de terem sido alunas de alguns professores renomados e prestigiados em âmbito nacional. Estas entrevistas fazem parte do acervo do Projeto Memória do Instituto de Educação do Rio de Janeiro. 
maior capital social e/ou cultural (BOURDIEU, 2000) em virtude de sua consagração na rede pública secundária e da formação universitária em cursos de filosofia, ciências e letras. Ademais, seu prestígio muito se deveu ao acesso por concurso e a sua posição de catedráticos; b) a "prata da casa” - professores cuja formação inicial ocorreu no próprio Instituto de Educação e, após qualificação obtida em nível superior, ingressaram como professores do curso normal, chegando alguns a atingir a cátedra das disciplinas pedagógicas; c) professoras-assistentes cuja única formação, na maioria das vezes, ocorreu no âmbito de escolas normais, em nível secundário. O ingresso no curso normal do Instituto deu-se por meio de convite dos catedráticos devido à atuação destacada na rede pública primária.

Este artigo discute, particularmente, a trajetória de dois professores "notáveis", que se destacavam pela distinção e legitimidade que conferiam ao curso, em grande parte devido ao prestígio como catedráticos concursados e pelo capital social ${ }^{4}$ acumulado ao transitarem por importantes espaços acadêmicos e/ou político-administrativos. Além disso, notabilizaram-se como autores de livros e manuais didáticos de grande alcance, com inúmeras edições e ampla circulação em cursos de formação de professores em território nacional.

Ao consultar depoimentos de antigas alunas que se encontram disponibilizados no Centro de Memória do Instituto de Educação, percebemos que estas manifestavam, deforma recorrente, o orgulho de terem sido alunas de sujeitos pertencentes a um corpo docente altamente prestigiado. Tornam-se evidentes nesses discursos manifestações de memória afetiva e apelos nostálgicos que impregnavam o imaginário dos sujeitos que transitaram pela instituição. O recorte temporal aqui considerado circunscreve-se a um período no qual a identidade dos professores e alunos

4 A categoria capital social aqui utilizada baseia-se na concepção de Bourdieu que define capital social como um conjunto de recursos potenciais que estão ligados à posse de uma rede durável de relações mais ou menos institucionalizadas de interconhecimento e de inter-reconhecimento ou à vinculação a um grupo por meio de ligações permanentes e úteis. $\mathrm{O}$ volume de capital social que um indivíduo possui depende da extensão da rede de relações que ele pode efetivamente mobilizar e do volume de capital (econômico, cultural ou simbólico) que é posse exclusiva de cada um daqueles a quem está ligado. Cf. NOGUEIRA e CATANI, 2001, p. 67.
Os notáveis

do instituto de educação: professores catedráticos do curso normal nos anos 1950-60
Educ. Foco, Juiz de Fora, 
encontrava-se fortemente vinculada a um programa institucional que ensejava promover a socialização destes ao estabelecer normas, comportamentos e ações a serem seguidas (DUBET, 2006).

O discurso dos sujeitos, bem como a análise de periódicos institucionais e anuários publicados por iniciativa de alguns diretores na década de 1950-60, já explorados por Lopes (2006), permitiu perceber esse processo de socialização, na medida em que procuravam transmitir aos destinatários a impressão de uma escola coesa e unificada. Em nosso entender, um verdadeiro espirito de grupo manifestava-se nos discursos veiculados nessas publicações que rememoram com orgulho a competência profissional de seus docentes, publicam e republicam os nomes dos membros da Congregação, incluindo mesmo os jubilados ou falecidos. Esses suportes físicos e simbólicos, plenos de significados, cumprem sua função, numa tentativa insistente de lembrar a todos - alunos, professores, funcionários, visitantes - o prestígio daquela instituição que se assentava, indiscutivelmente, no valor e no reconhecimento de seu corpo docente.

Nos limites desse artigo focalizaremosas trajetórias de dois professores catedráticos: Vicente Costa Tapajós (1916-1998) e Evanildo Cavalcante Bechara (1928). Nessa perspectiva, o recurso à abordagem biográfica tornou-se ferramenta útil, na medida em que tentamos reconstituir percursos de formação e trajetórias acadêmicas e profissionais dos docentes aqui retratados. $\mathrm{O}$ gênero biográfico, frequentemente criticado por pretender dotar a história de vida de uma racionalidade que ela, efetivamente, não possui (BOURDIEU, 1996), vem sendo revigorado desde o final da década de 1970 em razão do advento das experiências no campo da história do cotidiano, das minorias, da cultura popular (LORIGA,1998). Ainda assim, por muito tempo, parece que o gosto pelo singular só sobreviveu em escassos espaços da historiografia graças ao sucesso da prosopografia, espécie de "biografia coletiva" que "não é a de uma pessoa singular e sim de um indivíduo que concentra diversas características de determinado grupo" (LEVI, 1996, p.174). Nessa perspectiva, entendemos que, muitas vezes, por 
meio do estudo da trajetória de um personagem é possível interpretar a rede de relações na qual ele se insere, o que pode contribuir para a percepção do funcionamento efetivo das regras e normas em determinado contexto social.

O marco teórico dessa pesquisa ampara-se nas reflexões do sociólogo François Dubet a respeito das profissóes que se dedicam ao trabalho sobre o outro, onde se percebe uma participação ativa no processo de socialização dos indivíduos. $\mathrm{Na}$ obra que nos serve como referência, El declive de la institución, Dubet (2006) defende a hipótese de que durante muito tempo, o "trabalho sobre os outros" foi concebido como um "programa institucional" por meio do qual se processava uma forma de socialização realizada pela própria instituição em relação aos sujeitos que a integram sob a forma de transmissão/inculcação de valores, princípios e tradições. No caso específico da instituição escolar, essa socialização não se efetiva apenas na relação dos docentes com seus alunos, mas nas condutas e comportamentos que os próprios sujeitos (alunos, professores, gestores, funcionários) incorporam e que os fazem sentir mais ou menos comprometidos ou prestigiados por fazerem parte daquela instituição.

Foram também relevantes para essa pesquisa as contribuições de Dubar (2005) sobre identidade social, ou seja, a identidade que se constrói na relação entre a dimensão social e a dimensão individual ao longo da trajetória do sujeito. A teoria apresentada pelo autor tem como ponto de partida a articulação entre esses dois processos identitários. O primeiro trata da atribuição da identidade e decorre da interação das instituições e agentes com o indivíduo e deve ser analisado no interior dos sistemas de ação nos quais ele se insere; neste caso são legitimadas categorias que são impostas coletivamente e conferem ao sujeito uma identidade social virtual. O outro se refere à incorporação da identidade pelos próprios indivíduos, levando-se em conta as trajetórias por meio das quais eles constroem a identidade para si, também denominada identidade social real. Nesse segundo processo, a legitimidade irá depender daquilo que tem significado "subjetivo" para o indivíduo. Dessa forma, a identidade social resultaria da articulação entre essas duas dimensões, já que ambas se encontram presentes na trajetória dos indivíduos.

Educ. Foco, Juiz de Fora, do instituto de educação: professores catedráticos do curso normal nos anos 1950-60 
As fontes documentais que servem ao estudo foram selecionadas no acervo do Centro de Memória da Educação Brasileira do Instituto Superior de Educação do Rio de Janeiro - CMEB/ISERJ (fichas funcionais, livros de designações, obras e livros didáticos produzidos pelos professores) e no Programa de Estudos e Documentação Educação e Sociedade da Universidade Federal do Rio de Janeiro - PROEDES/ UFRJ (relação de alunos, horários e planos de ensino da Universidade do Distrito Federal - UDF).

Além dessa documentação, foram utilizadas entrevistas produzidas com ex-alunas e disponibilizadas pelo Projeto Memória - ISERJ, bem como o depoimento de um dos professores da instituição no período referido. Em sintonia com os objetivos da pesquisa, utilizamos a história oral, aqui entendida como um instrumento teórico-metodológico que "enfatiza fenômenos e eventos que permitem, através da oralidade, oferecer interpretações qualitativas aos processos histórico-sociais" (LOZANO, 1996, p. 16).

\section{TRAJETÓRIAS DE “PROFESSORES NOTÁVEIS”}

O exame das fontes documentais, bem como a análise das entrevistas, indicaram que os professores mais reconhecidos pelo alunado eram os catedráticos que se dedicavam a lecionar disciplinas específicas da escola secundária ${ }^{5}$. Tal fato talvez se explique pela titulação obtida em universidades de prestígio e em campos do conhecimento socialmente valorizados. Outras razóes, porém, podem explicar esse prestígio, sendo possível conjecturar, por exemplo, que esses docentes desfrutavam de contatos sociais que lhes conferiam condições mais favoráveis para transitar em círculos acadêmicos e/ ou profissionais extremamente relevantes. Ademais,

5 Refiro-me aqui à escola secundária propedêutica, conforme disposto pela Reforma Capanema (1942), que na época era dividida em dois ciclos: o ginásio de quatro anos e o colegial com três anos de duração. Em depoimentos prestados ao Projeto Memória (Promemo/ISERJ) algumas ex-alunas, estudantes nas décadas de 1950-60, manifestaram orgulho de terem sido alunas de professores catedráticos que atuavam tanto no ginásio quanto no curso normal, sendo os mais citados: Evanildo Bechara (Português e Literatura), Dirce Riedel (Português e Literatura), Ary Quintella (Matemática) e Vicente Tapajós (História). 
apresentavam-se como autores de livros didáticos de repercussão nacional, publicados por editoras de grande alcance e frequentemente adotados por escolas secundárias de prestígio.

Na concepção de Dubet (2006), a escola secundária foi tradicionalmente percebida como escola da grande cultura e da elite, chegando a afirmar que "no ensino secundário, todos os atores, ou quase todos, sentem nostalgia de um liceu tradicional, aqueles que eles conheceram ou aquele com que eles sonharam" ( $p$. 131). Assim, defende a hipótese de que os professores secundários, em sua maioria, percebem-se mais como filósofos, matemáticos, historiadores, físicos ou literatos do que como professores.

Em seus estudos sobre o ensino secundário dos anos de 1940-50, Norberto Dallabrida (2012) também o percebe como um nível de escolarização elitizado, afirmando que somente a partir dessa época, "por iniciativa do Governo e da sociedade civil, parcelas das classes médias e populares foram incorporadas à escola secundária” (p. 155).

Essa reflexão sobre a identidade do professor secundário talvez explique a representação de distinção dos docentes aqui retratados no imaginário daqueles que passaram pelo Instituto, especialmente no contextodaépoca aqui focalizada. Ainda que se tratasse, reconhecidamente, de uma escola de formação de professores, os catedráticos das disciplinas pedagógicas não chegaram a desfrutar do mesmo prestígio dos que abraçavam as disciplinas da escola secundária propedêutica. Isso pode ser explicado pela excelência do ginásio, cursado antes do normal, onde alunas submetidas a um processo seletivo exigentíssimo desfrutavam desde cedo das aulas desses notáveis, muitos dos quais as acompanhariam na fase seguinte, durante o curso normal ${ }^{6}$.

6 Até o final da década de 1950 a única forma de ingressar no Instituto de Educação dava-se pela escola secundária em nível ginasial. Com a criação de outras escolas oficiais, o acesso ao curso normal do Instituto foi permitido a jovens oriundas de outras escolas, mediante concurso de provas sempre muito difíceis, devido à grande demanda de jovens pela instituição.

Educ. Foco, Juiz de Fora, v. 21, n.2, p. $423-446$, maio/ago. 2016 
A título de exemplo, analisaremos o percurso de formação e a trajetória profissional de dois catedráticos que reuniam as condições aqui elencadas: Vicente Tapajós e Evanildo Bechara.

Vicente Costa Santos Tapajós (1916-1998) nasceu em Petrópolis, cidade serrana do Estado do Rio de Janeiro e estudou no Colégio Pedro II onde foi aluno de Jonathas Serrano, João Ribeiro, D’Escragnolle Dória e Delgado de Carvalho, professores que "marcaram sua vida"”. Cursou a Escola de Economia e Política da Universidade do Distrito Federal (UDF), onde ingressou no curso de História em 1935 e, após um curso intensivo, sem direito a férias, formou-se em dezembro de 1937 na primeira e única turma dessa instituição, uma vez que as turmas posteriores foram absorvidas, em 1939, pela nova Faculdade Nacional de Filosofia ${ }^{8}$. Ali foi aluno de Pierre Defontaines (Geografia), Eugène Albertini, especialista em História Romana, Gilberto Freyre (Antroplogia) e de Sérgio Buarque de Holanda, que estreava na vida acadêmica como assistente do professor francês Henri Hauser, contratado para lecionar História Moderna e Econômica naquela universidade. ${ }^{9}$

Atuou como representante de sua turma junto ao diretório acadêmico da UDF, mas segundo depoimento prestado a Marieta Ferreira (2013), “o coletivo tendia mais

7 Depoimento prestado a Marieta Moraes Ferreira em 1994. Cf. Ferreira (2013)

8 A Universidade do Distrito Federal foi criada na cidade do Rio de Janeiro por iniciativa de Anísio Teixeira em 1935. Foi a primeira instituição carioca a manter cursos de formação de professores para a escola secundária, cargo até então ocupado por autodidatas e profissionais liberais sem qualquer formação específica. Essa universidade foi extinta em janeiro de 1939 tendo a oportunidade de formar uma única turma de alunos que cursaram os três anos dos diversos cursos que a compunham. Ver a respeito da história da UDF: Mendonça (2002), Fávero (2004), Lopes (2008), Fávero e Lopes (2009).

9 Sobre a atuação dos professores franceses nas universidades brasileiras, em especial na Universidade do Distrito Federal e na Faculdade Nacional de Filosofia da Universidade do Brasil, ver os trabalhos de Ferreira (2006; 2008). 
para o estudo; a política era muito secundária” (p. 166). Aliás, no contexto dos anos 1930, quando fervilhavam ideias

políticas bastante polarizadas, Tapajós manteve-se ligado à Igreja e não se filiou a qualquer grupo político. Já no período da redemocratização, em 1945, declarouse antigetulista, apoiando a UDN e Carlos Lacerda, cujo governo no Estado da Guanabara, foi em seu entender "admirável, principalmente nas áreas de urbanismo e educação" (idem, p. 167).

Mas foi Jayme Coelho, professor de história antiga e responsável pela disciplina Prática de ensino em história da Escola de Educação da UDF, quem o convidou a ser seu assistente no Instituto de Educação, o colégio de aplicação da UDF onde os futuros professores secundários realizavam seu estágio.

Em 1948 prestou concurso para a Prefeitura do Distrito Federal e, uma vez efetivado no cargo, foi transferido para o Instituto de Educação como professor de História. Acumulou funções docentes no Colégio Pedro II, na Universidade do Brasil, atual UFRJ, na Universidade Santa Úrsula ${ }^{10}$ e no Instituto Rio Branco, destacando-se ainda como assessor de História da TV Educativa durante os anos de $1970^{11}$.

Ao ser designado para o Instituto de Educação, conforme entrevista concedida a Zilá Enéas ${ }^{12}$ (1998), sentiu-se um pouco temeroso pois,

$$
\begin{aligned}
& \text { (...) aquele estabelecimento modelar, } \\
& \text { aparecia-me como um templo, } \\
& \text { um lugar sagrado no campo da } \\
& \text { educação, não apenas pelos mestres } \\
& \text { que o idealizaram e o construíram, }
\end{aligned}
$$

$10 \mathrm{Na}$ Universidade Santa Úrsula foi assistente de Pedro Calmon, tornando-se titular de História do Brasil, disciplina que lecionou até 1984.

11 Dados biográficos disponíveis em www.ihgb.org.br Acesso em 12 de março de 2013.

12 Zilá Enéas foi aluna de Vicente Tapajós, autora do livro Era uma vez no Instituto de Educação (1998). A entrevista foi concedida em 19 de maio de 1994.

Educ. Foco, Juiz de Fora, v. $21, n .2$, p. $423-446$ maio/ago. 2016 
mas todo o corpo docente, reconhecidamente selecionado como o discente, vencedor do severo combate do exame de admissão com provas escritas e orais eliminatórias. A própria majestade do prédio, o prestígio nacional de que a casa desfrutava como laboratório de novos métodos e técnicas de ensino, tudo fazia crescer nossa responsabilidade, impondo-nos dedicação sempre maior e crescente aperfeiçoamento científico e didático. [Mas] esse temor foi, assim, um estímulo (...) e o Instituto de Educação tornou-se parte fundamental da minha vida, a glória maior de uma longa carreira de magistério (p. 101).

A influência do movimento da Educação Nova em sua formação é significativa, como podemos depreender de seu depoimento. Para ele, "a UDF era a Escola Nova" (Ferreira, 2013, p. 164), sugerindo que tanto o Instituto quanto a Universidade foram concebidos como campos de aplicação daquele ideário pedagógico. Estabelecimento modelar, templo, lugar sagrado da educação são expressões que reforçam a monumentalidade conferida à instituição por seus criadores, em especial Fernando de Azevedo ${ }^{13}$.

Em 1961, após tornar-se catedrático de História no Instituto de Educação, Tapajós abriu mão da cátedra no Colégio Pedro $\mathrm{II}^{14}$. A nostalgia e o apego ao "passado idílico" da instituição foram revelado sem depoimento prestado à ex-aluna Zilá Enéas, a quem confidenciou que após a aposentadoria, ao passar pelo Instituto ou visitá-lo,

13 A respeito da memória construída pelos principais signatários do Manifesto de 1932 e pela criação do Instituto de Educação do Rio de Janeiro, ver Lopes (2006).

14 O concurso foi respaldado pelo Decreto n. 514 de 7 de julho de 1961.Vicente Tapajós obteve a primeira colocação no concurso de provas e títulos para professor catedrático do Instituto. Informação constante da ficha funcional do professor localizada no CMEB/ISERJ. 
sentia-se profundamente triste e decepcionado, ao percebêlo "envelhecido e decadente" (Enéas, 1998, p. 102).

Em entrevista concedida a Ferreira (2013), declarou ter-se dedicado mais ao magistério do que à pesquisa, pois "precisava sobreviver, manter a família, e a pesquisa implicava a renúncia a horas de trabalho" (p. 169). Apenas nas férias, recorria ao Instituto Histórico e Geográfico (IHGB) ou ao Arquivo Nacional a fim de atualizar seus conhecimentos através das pesquisas que realizava. Nessa entrevista afirmou que "chegava a dar 15, 16 aulas por dia das sete da manhã às 11 horas da noite", já que "sem fortuna de família (...) tinha que se sacrificar" (idem).

No âmbito do curso normal do Instituto exerceu o cargo de coordenador de disciplina (História), além de integrar diversas comissóes e bancas de concursos para a rede pública de ensino. Em 1965, na condição de catedrático, participou da criação do Curso de Formação de Professores para o Ensino Normal (CFPEN), curso superior criado no Instituto de Educação e extinto dez anos depois. $\mathrm{Na}$ verdade, o CFPEN almejava formar professores para lecionar no curso normal, prerrogativa que desde 1939 pertencia ao curso de Pedagogia da Faculdade Nacional de Filosofia da Universidade do Brasil. Mas alguns catedráticos do Instituto apostaram na iniciativa e justificavam a criação do curso (que concorreria com o ministrado pelas faculdades de filosofia), alegando que a demanda por formação de professores primários era muito grande e os egressos da universidade não davam conta de suprir as necessidades da rede, tendo em vista que nos anos de 1960 eram seis as escolas normais oficiais do então Estado da Guanabara (1960-1975) ${ }^{15}$. Entretanto, em razão da Reforma Universitária de 1968 (Lei n. 5540/68), houve sugestão para que o curso fosse suprimido, o que somente aconteceu em 1975, quando os alunos egressos do CFPEN tiveram que complementar seus estudos na Universidade

15 Até 1946 só existia o Instituto de Educação como instituição oficial destinada a formar professores primários para a rede pública da cidade do Rio de Janeiro. Neste ano, foi inaugurada a Escola Normal Carmela Dutra e nos anos de 1960 foram criadas as Escolas Normais Heitor Lira, Júlia Kubitscheck, Sara Kubitscheck e Inácio Azevedo Amaral.

Educ. Foco, Juiz de Fora, v. 21, n.2. p. $423-446$ maio/ago. 2016 
do Estado do Rio e Janeiro (UERJ) para que fizessem jus aos diplomas de graduação.

Como coordenador de disciplina, Tapajós desfrutava de carga horária reduzida e dispunha de diversos assistentes, destacando-se entre eles a professora Maria Eduarda Fernandes ${ }^{16}$ que seguia rigorosamente os programas por ele elaborados, além de recomendar aos alunos a leitura dos manuais didáticos de autoria do professor ${ }^{17}$.

Autor de inúmeros compêndios de História, reeditados sucessivamente entre os anos de 1954 e 1979, também produziu biografias, dicionários e artigos científicos, estes especialmente publicados na Revista do Instituto Histórico e Geográfico Brasileiro (IHGB), instituição da qual se tornou membro e integrante da Comissão de Pesquisas e Históricas, além de ocupar a presidência entre 1992 e $1995^{18}$. São de sua autoria, ainda, diversos artigos sobre educação publicados na revista Escola Secundária, da Diretoria do Ensino Secundário do Ministério da Educação.

Entre 1957 e 1965 participou da Campanha de Aperfeiçoamento do Ensino Secundário (MEC) ministrando cursos destinados à formação de professores leigos em cidades do interior, onde não havia faculdades. As aulas ocorriam nos meses de férias, em janeiro e fevereiro

16 Maria Eduarda Fernandes diplomou-se em História pela Faculdade Nacional de Filosofia da Universidade do Brasil em 1953, conforme ficha de matrícula obtida no arquivo da Faculdade Nacional de Filosofia da Universidade do Brasil (FNFi/ UB) sob a guarda do Proedes/UFRJ. Lecionou a disciplina História do Brasil que integrava o currículo do primeiro ano do curso normal.

17 Dados obtidos por meio de consulta às entrevistas de ex-alunas, disponibilizadas pelo Projeto Memória-ISERJ.

18 Dentre as principais publicações de Vicente Tapajós destacam-se os livros: História do Brasil (1946, 1963), História da América (1954, 1956, 1979), Compêndio de História Geral (1956, 1965), Compêndio de História do Brasil (1958), Compêndio de História da América (1959), Manual de História do Brasil para o curso ginasial (1960), História administrativa do Brasil (2 volumes, 1956), O regime de Capitanias Hereditárias (1962), História do desenvolvimento econômico do Brasil (1969), História Geral - Curso Colegial (1971), Duarte (1993). 
e, às vezes, durante o mês de julho. Ao todo, foram 17 cursos de história e geografia, assim como das respectivas didáticas. Possuíam caráter essencialmente prático, visando ao preparo e capacitação dos alunos-professores para o exercício da docência (FERREIRA, 2013).

Em consulta a sua ficha funcional foi possível constatar a concessão de licenças para afastamento do país, em razão de pesquisas realizadas junto ao Instituto de Alta Cultura do Ministério de Educação Nacional em Portugal (1957) e de viagens de estudos aos Estados Unidos da América do Norte (1967), "com direito à percepção de vencimentos e demais vantagens como estagiário da Escola Superior de Guerra”. ${ }^{19}$

Por ocasião das comemorações do sesquicentenário da independência do Brasil (1972), Tapajós foi designado pela direção geral para planejar e coordenar as atividades de participação do Instituto de Educação naquela solenidade ${ }^{20}$. Catedrático responsável pelo curso de Didática dos Estudos Sociais, foi autor dos programas de Educação Moral e Cívica e Estudo de Problemas Brasileiros, disciplinas obrigatórias para todos os cursos do CFPEN. Com a extinção desse curso em 1975, voltou a lecionar no curso normal até a aposentadoria em $1983^{21}$.

Evanildo Cavalcante Bechara nasceu no Recife em 1928 e aos doze anos, órfão de pai, transferiu-se para o Rio de Janeiro a fim de completar seus estudos, passando a residir na casa de um tio, no bairro do Méier, zona norte da cidade. Estudou no modesto Colégio Leverger, cujo dono era um coronel amigo de seu tio, também militar. A disciplina que mais gostava era a matemática,

19 Cf a ficha funcional deste professor, o mesmo foi autorizado a afastar-se pelo Processo n. 03/23.203/67. Ordem de Serviço P, n. 2194 de 18/8/1967, publicado no BOE 808 de 21/8/1967. Arquivo CMEB-ISERJ

20 De acordo com a Ordem de Serviço de 13 de março de 1972. Arquivo CMEBISERJ

21 Processo n. E-03122862/1983 publicado no BOE de 14/02/1984. Arquivo CMEB-ISERJ

Educ. Foco, Juiz de Fora, v. $21, n .2, p .423-446$, maio/ago. 2016 
pois queria seguir carreira militar como engenheiro aeronáutico.

Segundo depoimento prestado a esta pesquisa, ${ }^{22}$ enfatizou que "desde muito cedo se sentiu atraído pelo magistério", mas pensava em ser professor de matemática. Aliás, para sobreviver e auxiliar a família que ficara no nordeste, dava aulas particulares, especialmente de matemática e latim, dificuldade maior dos alunos da escola secundária. Entretanto, ainda muito jovem, conheceu o professor Manuel Said Ali (eminente estudioso da língua portuguesa) e essa experiência lhe permitiu trilhar caminhos no campo dos estudos linguísticos. Ingressou no curso de Letras na Faculdade de Filosofia, Ciências e Letras do Instituto La-Fayette ${ }^{23}$, tendo concluído os estudos superiores em 1948, aos vinte anos de idade.

$\mathrm{Na}$ época havia poucos concursos, o que reduzia o mercado de trabalho a algumas escolas privadas. Em 1954, houve concurso para a Prefeitura do Distrito Federal ${ }^{24}$, para a Escola Técnica Nacional ${ }^{25}$ e para o Colégio Pedro II. Aprovado nos dois primeiros, Bechara passou a acumular cargos na esfera municipal e federal.

Inicialmente lotado no Colégio Visconde de Cairu, no bairro do Méier, onde residia, acabou sendo remanejado para o Instituto de Educação por interferência de Cândido Jucá Filho, à época elemento de prestígio junto à Secretaria de Educação, além de professor catedrático de português do Instituto de Educação e do Colégio Pedro II.Segundo

22 Evanildo Bechara. Entrevista à pesquisadora na sede da Academia Brasileira de Letras, no Rio de Janeiro,em 16 de novembro de 2011. Acompanharam esta entrevista as bolsistas de Iniciação Científica Patricia Gurgel e Sarah Rocha.

23 Tratava-se de uma faculdade privada de muito prestígio no Rio de Janeiro. Durante a década de 1950 uniu-se a outras faculdades e deu origem à Universidade do Distrito Federal que, a partir de 1960, passou a denominar-se UEG (Universidade do Estado da Guanabara) e atualmente UERJ (Universidade do Estado do Rio de Janeiro).

24 Até o ano de 1960 a cidade do Rio de Janeiro detinha o posto de capital do país denominando-se Distrito Federal. 
o entrevistado, a lotação no Instituto foi feita a sua revelia, pois Candido Jucá havia sido membro da banca para o concurso de catedrático do Pedro II ao qual Bechara se submetera. Neste concurso, apesar de não lograr aprovação na defesa de tese, obteve grau dez na prova escrita de todos os examinadores, fato que teria despertado a admiração de Jucá Filho, o qual, mesmo sem consultá-lo, decidiu transferi-lo para a instituição de maior prestígio da rede escolar do Distrito Federal.

De acordo com Bechara, "mesmo contra a vontade" passou a lecionar na escola secundária do Instituto. Poucos anos depois, prestaria concurso e obteria aprovação para o cargo de catedrático do curso normal, tendo sido também aprovado no concurso para catedrático de língua portuguesa do Colégio Pedro II. ${ }^{26}$

Em 1965, durante a gestão do Secretário de Educação, professor Flecha Ribeiro, recebeu convite para compor o Conselho Estadual de Educação. Cedido a este órgão, lá permaneceu até 1974 quando retornou ao Instituto para ocupar o cargo de diretor-geral, função na qual se manteve apenas um ano, ${ }^{27}$ vindo a se aposentar em 1982.Cf ficha funcional, o referido professor foi nomeado em cargo comissionado para a direção geral do Instituto de Educação em 26/03/1974 na vaga decorrente da exoneração do professor Nilson de Oliveira. Manteve-se no cargo até 09/04/1975 quando foi exonerado a pedido. Arquivo CMEB-ISERJ.

Embora sua passagem como catedrático do curso normal na década de 1960 tenha sido breve (1961-1965), curiosamente, Bechara é apontado pelas alunas como um dos mais "notáveis" professores que por lá passaram. Essa deferência das alunas, em parte se deve ao grande prestígio

$26 \mathrm{Na}$ ficha funcional de Evanildo Bechara encontramos referência ao Boletim Oficial do Estado da Guanabara (BOE, n. 36) datado de 25/5/1964 que autorizava a acumulação dos cargos de professor catedrático da escola secundária do C. Pedro II e do curso normal do Instituto de Educação. Arquivo CMEB-ISERJ.

27 Cf ficha funcional, o referido professor foi nomeado em cargo comissionado para a direção geral do Instituto de Educação em 26/03/1974 na vaga decorrente da exoneração do professor Nilson de Oliveira. Manteve-se no cargo até 09/04/1975 quando foi exonerado a pedido. Arquivo CMEB-ISERJ.

Educ. Foco, Juiz de Fora, v. 21, n.2. p. $423-446$ maio/ago. 2016 
de que ainda hoje desfruta como gramático filólogo e membro da Academia Brasileira de Letras. Trata-se aqui de uma forma de evocar lembranças antigas à luz da realidade atual, o "passado filtrado pelas lentes do presente", como ensina Lowenthal (1998, p.115)

Nas diversas biografias consultadas sobre o “imortal"não encontramos mençõesa sua passagem pelo Instituto na condição de professor; apenas breves referências ao cargo de direção que ocupou entre 1974 e 1975. Indagado sobre esse silêncio, Bechara atribuiu-o à queda de prestígio da instituição nas últimas décadas: "O Instituto era uma instituição muito prestigiada, mesmo com a chegada das outras escolas [normais], o IE sempre foi uma instituição de proa, ao lado do Colégio Militar e do Colégio Pedro II... Eram as três grandes [instituições]" (BECHARA, 2011).

Entretanto, revelou que em seu retorno ao Instituto na década de 1970, já na condição de diretor, percebeu que "o Instituto começara a cair":

(...) havia uma coisa muito importante: as alunas que saiam do curso normal, já saiam empregadas... Eu peguei essa fase que, infelizmente, já não existia mais. Então, isso fez cair muito... (...) Primeiro, colaborou o fato de se abrirem muitas escolas normais, não é? Nós chegamos a ter, se não me engano, eram cinco ou seis... Mas quando se permitiu que os alunos das escolas... privadas pudessem prestar o concurso ${ }^{28}$, aí a coisa...piorou (Idem).

Sobre o processo de democratização da escola com o ingresso de alunos egressos de camadas populares, manifestou-se

28 Até o ano de 1969, inclusive, os egressos das escolas normais públicas (oficiais) tinham acesso automático à rede primária do então Estado da Guanabara. A partir daí, o acesso deu-se somente por concurso aberto a todos os concluintes de cursos normais, tanto públicos quanto privados. 
De fato, o IE sofreu por ser uma escola que recebia uma clientela muito selecionada (...) e o perfil da normalista mudou completamente, pois antes havia uma preparação extraordinária, primeiro pela própria classe social de onde elas procediam. Era um concurso democrático, mas era um concurso que selecionava pelo valor. Não havia como hoje, por exemplo, esse problema de cotas... havia o valor intelectual e o resultado das provas. Então houve, realmente, não uma democratização do ensino, mas uma popularização do ensino. E vieram uma série de medidas como... por exemplo, em relação à língua portuguesa. A língua portuguesa estava incluída num conjunto de disciplinas denominada Comunicação e Expressão... ${ }^{29}$ Então tinha música, tinha ginástica, essa coisa toda. Então às vezes um aluno que não estava bem numa disciplina, vamos dizer... mais importante para sua formação era beneficiado com as notas obtidas em outras...(...) A mudança foi substancial e o resultado é que a escola se desmoronou. A escola se desmoronou e até hoje não se reergueu (BECHARA, 2011).

A posição assumida pelo catedrático talvez explique o silêncio sobre sua experiência profissional no Instituto, ao contrário de outras instituições nas quais exerceu atividades paralelas como o Colégio Pedro II e a Faculdade de Filosofia, Ciências e Letras da Universidade do Estado da Guanabara (UEG) na qual ingressou a convite do professor Antenor Nascentes. Nessa mesma universidade obteria o título de Doutor em Letras (1964) chegando à cátedra de Filologia Românica, disciplina que lecionou até

29 Reforma curricular realizada pela lei n. 5692/1971.
Os notáveis

do instituto de educação: professores catedráticos

do curso normal

nos anos 1950-60
Educ. Foco, Juiz de Fora, v. $21, n .2$, p. $423-446$, maio/ago. 2016 
1992, quando se aposentou. Lecionou ainda no Instituto de Letras da Universidade Federal Fluminense (UFF) entre 1976 e 1994, sendo também professor visitante da Universidade de Colônia (Alemanha) na década de 1970 e na Universidade de Coimbra (Portugal) nos anos de 1980.

Membro titular da Academia Brasileira de Filologia, da Sociedade Brasileira de Romanistas e do Círculo Linguístico do Rio de Janeiro, tornou-se também sócio da Academia de Ciências de Lisboa e da Academia Internacional de Cultura Portuguesa. Convidado por acadêmicos amigos para candidatar-se à Academia Brasileira de Letras ocupa até hoje a cadeira de Afrânio Coutinho.

Evanildo Bechara produziu vasta obra composta por dezenas de manuais, compêndios, antologias, ensaios, dicionários, mas seu trabalho de maior repercussão foi a Moderna Gramática Portuguesa com mais de quarenta edições:

Olha, a minha gramática foi publicada pela primeira vez em 1961. Pois bem, na década de 70 o diretor presidente da Editora Nacional me declarou que a editora já tinha vendido mais de dois milhões de exemplares da gramática. Porque a Editora Nacional era uma editora que em qualquer estado a que você fosse você tinha um setor, de modo que era uma editora pujante que mandava o livro para todas as partes do Brasil. Mas o que se ganhava com livros era pouco... Agora, havia professores, autores de livros que faziam uma política do seu livro. Visitavam os colegas, não é, distribuíam os livros, etc... (BECHARA, 2011). 
desses docentes é bem mais complexa e contraditória e merece ser problematizada. Seriam lembrados pelas aulas memoráveis que ali ministraram? Ou se tornaram "inesquecíveis" pela aura de legitimidade que emprestavam à instituição, tendo seu nome sempre associado ao sucesso editorial de seus livros e aos altos cargos ocupados em universidades de prestígio, bem como em círculos acadêmicos bastante valorizados pela mídia e pela memória coletiva?

Oriundos de escolas secundárias de cunho propedêutico, mas muitas vezes desprovidos de capital econômico e social, certamente curvaram-se às necessidades de obter salário e reconhecimento à custa de seu trabalho, como no caso de Evanildo Bechara que chegou a acumular diversos empregos em um mesmo espaço de tempo. Entretanto, em razão de sua formação em cursos universitários socialmente valorizados e pelos esforços empreendidos em estudos que resultaram aprovações nos concursos aos quais se submeteram, tornaram-se profissionais bem sucedidos e reconhecidos tanto na instituição quanto nos meios acadêmicos pelos quais circulavam com desenvoltura. Souberam, portanto, capitalizar seus esforços e tirar partido de contatos sociais que lhes facilitaram o acesso a diversas instâncias acadêmicas e/ou político-administrativas, alcançando sucesso na trajetória profissional.

$\mathrm{Na}$ condição de catedráticos e coordenadores de disciplinas e também em função dos vários compromissos acadêmicos (afinal, quase todos acumulavam cargos em escolas de prestígio como o Colégio Pedro II e até mesmo em universidades) talvez esse grupo seja o que menos contato teve com os estudantes. Entretanto, curiosamente, é o mais lembrado pelos ex-alunos que se sentiam distinguidos quando tinham o "privilégio" de tê-los como professores. São recorrentes os depoimentos de alunos que, relembrando sua trajetória discente, afirmam com indisfarçável orgulho terem sido alunos de professores "do porte de Evanildo Bechara, Vicente Tapajós, Leodegário de Azevedo Filho, Dirce Riedel” associando automaticamente a excelência do ensino

Educ. Foco, Juiz de Fora, v. 21, n.2, p. $423-446$, maio/ago. 2016 
oferecido pela instituição à qualidade de seu corpo docente, especialmente aos seus catedráticos.

\section{CONSIDERAÇÕES FINAIS}

Foi possível, por meio desta pesquisa, constatar a distinção atribuída a certos professores catedráticos do Instituto de Educação em razão da titulação obtida em áreas do conhecimento socialmente valorizadas e realizada em universidades de prestígio. Vicente Tapajós foi aluno da primeira e única turma da Universidade do Distrito Federal no curso de Economia e Política, na modalidade História. Evanildo Bechara diplomou-se em letras na Universidade La Fayette e ambos ingressaram no Instituto de Educação por meio de concursos públicos, tornandose catedráticos também por concurso no início dos anos 1960.

Numa época em que concursos eram menos freqüentes e a maioria dos docentes era contratada ou indicada para exercer o magistério no Instituto de Educação, essa forma de acesso acarretava distinção e prestígio. Os concursos para a cátedra foram usuais no final dos anos de 1920, durante a gestão de Fernando de Azevedo na Instrução Pública do Distrito Federal, na Escola Normal que antecedeu o Instituto de Educação, conforme observa Accácio (2002). Durante a década de 1930 e até o final da década seguinte esses certames não foram frequentes. A forma de acesso à carreira dava-se por indicação, contrato ou simples cessão de professores da rede pública municipal à instituição. No caso das disciplinas pedagógicas, grande parte do corpo docente era constituído por professoras primárias, sem qualquer formação superior, recrutadas a partir de critérios que valorizavam sua experiência e eficácia demonstrada no trabalho com suas turmas (LOPES, 2014).

$\mathrm{O}$ fato de se dedicarem ao ensino de disciplinas de formação geral também contribuiu, pois ainda que se tratasse de uma instituição voltada para formar o magistério primário, a essa época os normalistas já tinham condições 
A maioria dos professores responsáveis pelas disciplinas pedagógicas, mesmo ocupando a função de catedráticos, não desfrutava do mesmo prestígio dos que lecionavam disciplinas de formação geral, cujos conteúdos tornavamse imprescindíveis para o ingresso na universidade.

Para além da titulação que estabelecia diferenças de nível e da relação direta que se estabelece entre qualificação e salários, o prestígio conferido a certos docentes relacionava-se também ao capital social que detinham em razão das instâncias acadêmicas e/ou político-administrativas nas quais circulavam, como foi o caso de Vicente Tapajós, membro do Instituto Histórico e Geográfico Brasileiro (IHGB) e professor do Instituto Rio Branco. O mesmo ocorria em relação a Evanildo Bechara, que além de circular como docente em várias universidades tornou-se membro da Academia Brasileira de Letras e do Conselho Estadual de Educação. Outro fator de distinção pode ser atribuído à autoria de livros publicados por grandes editoras e que tiveram repercussão nacional, com dezenas de edições.

Esta pesquisa procurou demonstrar que, a despeito dos depoimentos, das publicações e das construções simbólicas operadas pelo programa institucional que objetivavam produzir um efeito de coesão e harmonia, foi possível detectar marcante diferenciação entre o corpo docente. Os "notáveis", aqui representados pelas duas trajetórias analisadas, ocuparam uma posição de poder e prestígio capaz de torná-los "inesquecíveis" aos olhos de quem vivenciou os nostálgicos anos dourados do Instituto de Educação do Rio de Janeiro.

\section{REFERÊNCIAS}

ACCÁCIO, L. Docentes e catedráticos: os concursos para professor da Escola Normal do Distrito Federal. Tese de Doutorado, Faculdade de Educação, USP, 2002.

\section{BECHARA, E. C. Entrevista à pesquisa em 16 de novembro de 2011.}

cursos como Pedagogia, História, Geografia e Letras. Em 1961 com a sanção da Lei de Diretrizes e Bases todos os ramos do ensino médio foram equiparados para efeito de acesso ao superior. Ver a respeito Cunha (2007)

Educ. Foco, Juiz de Fora, v. 21, n.2, p. $423-446$ maio/ago. 2016 
BOURDIEU, P. A ilusão biográfica. In: FERREIRA, Marieta; AMADO, Janaína (orgs). Usos e abusos da história oral. Rio de Janeiro: Editora FGV, 1996, p. 183-191.

CUNHA, L. A. A universidade temporã: o ensino superior da colônia à Era Vargas. 3. ed. São Paulo: Editora Unesp, 2007.

DALLABRIDA, N. Os incluídos do exterior: trajetórias sociais de ex-alunos bolsistas de um colégio de elite (1952-1961). In: LOPES, S. de C.; CHAVES, M. A história da educação em debate: estudos comparados, profissão docente, infância, família e igreja. Rio de Janeiro: Mauad/Faperj, 2012, p. 155-169.

DUBET, F. El declive de la institución - profesiones, sujetos e individuos ante la reforma del Estado. Traducción de Luciano Padilla. Barcelona, Espanha: Editorial Gedisa, 2006.

DUBAR. C. A socialização: construção das identidades sociais e profissionais. São Paulo: Martins Fontes, 2005.

ENÉAS, Z. S. Era uma vez no Instituto de Educação. Rio de Janeiro: Edição do Autor, 1998.

FÁVERO, M. de L.; LOPES, S. de C. (Orgs). A Universidade do Distrito Federal (1935-1939): um projeto além de seu tempo. Brasília: Liber Livro/CNPq, 2009.

FÁVERO, M. de L. A UDF, sua vocação política e científica: um legado para se pensar a universidade hoje. Pro-Posições, Campinas, SP, Faculdade de Educação da Unicamp, v. 15, n. 3 (45), p. 143-162, set./dez. 2004.

FERREIRA, M. de M.A História como ofício - a constituição de um campo disciplinar. Rio de Janeiro: FGV/Faperj, 2013.

- Perfis e trajetórias dos professores universitários de História no Rio de Janeiro. In: OLIVEIRA, Antonio Barbosa (org). Universidade: lugares de memória. Rio de Janeiro: UFRJ, Fórum de Ciência e Cultura, Sistema de Biblioteca e Informações, 2008, p. 235-268. 
- Notas sobre a institucionalização dos cursos universitários de História do Rio de Janeiro. In: GUIMARÃES, Manoel Salgado. (org.). Estudos sobre a escrita da história. Rio de Janeiro: 7 Letras, 2006, p. 139-161.

LEVI, G. Usos da biografia. In: FERREIRA, Marieta; AMADO, Janaína (orgs). Usos e abusos da história oral. Rio de Janeiro: Editora FGV, 1996, p.167-182.

LOPES, S. de C. Oficina de Mestres: história, memória e silêncio sobre a Escola de Professores do Instituto de Educação do Rio de Janeiro. Rio de Janeiro: DP\&A/Faperj, 2006.

- Um modelo autônomo e integrado de formação docente: a breve experiência da Universidade do Distrito Federal (1935-1939). Revista Contemporânea de Educação, v. 3, n. 5, p. 147-164, jan./jun. 2008.

- Perfis docentes: prestígio e hierarquia no Instituto de Educação do Rio de Janeiro (anos 1950-60). Revista Brasileira de História de Educação, v. 1, n. 1 (34), p. 251 271, jan./abr. 2014.

LORIGA, S. A biografia como problema. In: REVEL, Jacques. (coord.). Jogos de escalas: a experiência da microanálise. Tradução de Dora Rocha. Rio de Janeiro: Editora FGV, 1998, p. 225-249.

LOWENTHAL, D. Como conhecemos o passado. Projeto História, Revista do PPGH- PUC/SP, São Paulo, n. 17, p. 63-202, nov.1998.

LOZANO, J. E.Práticas e estilos de pesquisa na história oral contemporânea. In: FERREIRA, M.; AMADO, J. (Orgs). Usos \& Abusos da história oral. Rio de Janeiro: Editora FGV, 1996, p. 15-26.

MENDONÇA, A. W. Anísio Teixeira e a Universidade de Educação. Rio de Janeiro: EdUERJ, 2002.

Educ. Foco, Juiz de Fora, v. $21, n .2$, p.423-446, maio/ago. 2016 

de educação. 3. ed. Petrópolis, RJ: Vozes, 2001.

Data de submissão: outubro de 2015

Data de aceite: dezembro de 2015 